\title{
Smartphone based Public Transport Guidance: An Investigation of Potential Benefits
}

\author{
Liu, Tao; Jiang, Yu; Ceder, Avishai; Gasson, Rachel; Cheyne, Lorraine
}

Published in:

Proceedings of the 2019 IEEE Intelligent Transportation Systems Conference

Link to article, DOI:

10.1109/ITSC.2019.8916848

Publication date:

2019

Document Version

Peer reviewed version

Link back to DTU Orbit

Citation (APA):

Liu, T., Jiang, Y., Ceder, A., Gasson, R., \& Cheyne, L. (2019). Smartphone based Public Transport Guidance: An Investigation of Potential Benefits. In Proceedings of the 2019 IEEE Intelligent Transportation Systems Conference (pp. 245-250). IEEE. https://doi.org/10.1109/ITSC.2019.8916848

\section{General rights}

Copyright and moral rights for the publications made accessible in the public portal are retained by the authors and/or other copyright owners and it is a condition of accessing publications that users recognise and abide by the legal requirements associated with these rights.

- Users may download and print one copy of any publication from the public portal for the purpose of private study or research.

- You may not further distribute the material or use it for any profit-making activity or commercial gain

- You may freely distribute the URL identifying the publication in the public portal 


\title{
Smartphone-based Public Transport Guidance: An Investigation of Potential Benefits*
}

\author{
Tao Liu, Yu Jiang, Avishai (Avi) Ceder, Rachel Gasson, and Lorraine Cheyne
}

\begin{abstract}
With the rapid development of smartphone applications, real-time and readily available journey planning information is becoming an integral part of a public transport (PT) system. Smartphones and other mobile devices are information sources capable of contributing to "big-data", and while each traveler has specific preference when undertaking a trip. The objective of this study is to look at how readily available smartphone-based information containing elements that might influence the decisions of which trip to select, can be personalized. The potential effect of personalized data availability for PT users has been investigated by considering five key weighted factors: waiting time, travel time, fare cost, walking time, and number of transfers. The methodology is based on finding the $\mathrm{K}$-shortest path for travelers where the value of each link comprises the cost of the five weighted factors based on users' preferences. By incorporating weighted factors, users may lean toward the $2^{\text {nd }}$, or $3^{\text {rd }}$, etc., shortest path. A case study was conducted to look at five parallel PT routes with different journey attributes in the city center of Auckland, New Zealand. The results show that the satisfaction of the users improves as they achieve their desired trip under optimized conditions based on their preferences.
\end{abstract}

\section{INTRODUCTION}

The wide spread use of smartphone applications will have a significant impact on the transformation of future urban mobility [1]. In recent years, various smartphone-enabled new public transport (PT) systems are springing up across the world [2]. With respect to PT systems, Schweiger [3] found smartphone applications have increasingly developed to provide more comprehensive information to PT travelers before and during a trip. Governments increasingly recognize

*Research supported by the National Engineering Laboratory of Integrated Transportation Big Data Application Technology under the grant number CTBDAT201907.

Tao Liu is with School of Transportation and Logistics, Southwest Jiaotong University, Chengdu 611756, P.R. China, National United Engineering Laboratory of Integrated and Intelligent Transportation, Chengdu 610031, P.R. China, and National Engineering Laboratory of Integrated Transportation Big Data Application Technology, Chengdu 611756, P.R. China (corresponding author, phone: +86-028-87600165; fax: +86-028-87600165; e-mail: tao.liu@swjtu.edu.cn).

Yu Jiang is with the Division of Transport Modelling, Technical University of Denmark (DTU), Bygningstorvet 116B, DK-2800 Kgs. Lyngby, Denmark (e-mail: yujiang@dtu.dk).

Avishai (Avi) Ceder is with the Transportation Research Center, Department of Civil and Environmental Engineering, 20 Symonds Street, The University of Auckland, New Zealand, and Faculty of Civil and Environmental Engineering, Technion-Israel Institute of Technology, Haifa, 32000, Israel (e-mail: a.ceder@auckland.ac.nz).

Rachel Gasson is with the Transportation Research Center, Department of Civil and Environmental Engineering, 20 Symonds Street, The University of Auckland, New Zealand (e-mail: rachelgasson@hotmail.com).

Lorraine Cheyne is with NZ Transport Agency (NZTA), Auckland, New Zealand (e-mail: lorraine.houston@nzta.govt.nz). that as computer technology becomes both cheaper and more powerful, more Intelligent Transportation System (ITS) technologies will be deployed. For instance, the New Zealand Transport Agency considers that ITS offers the opportunity to take the performance of the transport system to a new level, dramatically improving the ability to communicate with travellers as well as to resolve operational issues in the transport network, and the smart devices, such as the smartphone, that many of us carry are a key component of ITS technology as a tool for data collation and dissemination [4]. Some researchers have found that real-time smartphone applications have positive impacts on society overall, creating economic, environmental and safety benefits [5].

This research looks at the opportunities for smartphone based guidance to improve the PT traveller's experience, by linking "big-data" by definition, the "extremely large data sets that may be analysed computationally to reveal patterns, trends, and associations, especially relating to human behaviour and interactions" with personal preferences, to enable the traveller to select the most desirable service option available to them. The objective is to identify a means to optimally select best suggestions of best routes to fit an individual user, for a display on his/her smartphone. A theoretical smartphone application is 'modelled' in which the user is provided with information of the most suitable service/route available, based on the PT attributes of most concern to that user. This will provide an understanding of the potential benefits which can be achieved through smartphone PT guidance.

\section{RELATED LITERATURE}

\section{A. Smartphone Opportunities in Improving PT Services}

There are a lot of opportunities of smartphone applications in transportation systems, such as route planning, ridesharing/carpooling, traffic safety, parking information provision, traffic data collection, and traveler information provision [6]. With respect to PT systems, the Global Mass Transit Report [7] listed 17 key smartphone applications for the transit industry, and a partial list comprising some 44 cities using smartphones technology for fare payments (e.g., mobile-point-sale), in addition to journey information and real-time service location information provision. Beyond just the basic mechanics of planning and paying for a journey, travelers are likely to have preferences over different features of a journey, that might even influence their decisions to make the journey or not. Commuting, whether by car or PT can be a cause of considerable stress. According to Cantwell et al. [8], the invasion of personal space and the sense of a lack of 
control over a situation are key factors in elevated stress levels of PT commuters. Smartphones allow PT operators to communicate directly with PT users, and importantly, information can be received prior to arriving at the stop. With smartphone technology travelers might avoid travelling on crowded services by accessing information on passenger loadings, and minimize negative experiences of unreliable PT or enduring long wait times, through accessing real-time information. Lai and Chen [9] found that user benefits resulting in increased satisfaction can be been shown to, in-turn, become operator benefits through passenger behavioral intentions and customer loyalty.

Personalized mobile applications have the potential to not only improve the convenience and satisfaction of people who choose to use PT, but also to enhance the mobility of those for whom driving is not an option. Carmien et al. [10] looked at the potential of smartphone applications to enrich the lives of people no longer, or not, able to drive, such elderly populations and those with developmental or other cognitive disabilities, who may be PT dependent. An example of this is "iBeacon" technology, used in buses and trolleybuses in Bucharest. The iBeacon alerts visually impaired transit users via an accompanying smartphone application with a voice output on their phone. The voice output advises the passenger when their bus is 50-60 meters away. The iBeacon also emits if a passenger is waiting for the bus, enabling the passenger to locate the correct bus. The application can be used to plot a route across the city.

In Auckland, New Zealand, Auckland Transport has developed two applications to guide PT users. One application provides users with journey advice as well as a limited amount of real time information. The second application requires the user to know their route and to enter their desired stops, in order for the application to provide more accurate information regarding bus service location. However, as the information is presented in two separate applications, it is not easy or quick for users to access the information required. From a user's perspective, it would be extremely beneficial if a smartphone, or a similar display unit, could provide recommendations as to the best movement options based on their personal criteria in relation to the specific trip they are making.

\section{B. PT Attributes}

Each user has varying preferences, and further, every trip a user makes has unique requirements depending on its purpose. Eboli and Mazzula [11] discussed how the features that describe a PT service or journey can be distinguished into those that 'more properly' describe the service, i.e., as journey time, service headway etc., and characteristics that depend more on customer preferences, e.g., comfort, (being less easily measurable). Estergar-Kiss and Csiszar [12] identified a 'framework of aspects' that might be used to evaluate a "smart multimodal journey planner". Some aspects of a PT trip or service will be of concern to both the user and the operator, although each party may have different interest in the particular trip attribute. This literature review covers attributes of a PT service/trip from the users' point of view.
- Cost - as the fare cost, may be a factor of generalized cost.

- Availability - being the frequency of the service and the duration for which the service is offered.

- Accessibility - can be determined by its distance, or the time taken to access the desired stop/station. Walton and Sunseri [13] found New Zealand data indicate a perceived reasonable walking distance to access sub-mode of travelling to the train station is around 820 meters.

- Service Connectivity - as a customer's ease of making a transfer from one system, i.e., one PT service provider or one mode, to another. Key factors for good service connectivity include synchronized schedule, quality transfer point information and amenities, pre-journey and en-route travelling information, and integrated fare policies with convenient collection [14-15].

- Information - the ease of finding which services are available, how well the services are running and whether, if there is a problem how easily an alternative service/route can be determined. Verhoef [16] found that information arranged by destination, as opposed to being provided by service i.e., departure time, enables passengers to better select the right service, and greatly reduced the delay resulting from the selection of the wrong service by approximately $75 \%$. The same study found that using a destination-based structure for departure information resulted in less time being required to search for a service, by around $40 \%$.

- Reliability - In a study attempting to capture the passenger's point of view, Eboli and Mazzulla [17] found service reliability to be one of the most important attributes for PT users when making choice options. On-time performance is one of the most common indicators used to measure service reliability.

- Comfort - the passenger's perception of journey comfort includes both in-vehicle physical comfort, and that of the ambient conditions on board or at stops. Measures of comfort may be made by looking at maximum and mean vehicle loadings and seat availability, and Vovsha et al. [18] showed that if a passenger has a less than $40 \%$ probability of getting a seat, he or she feels uncomfortable. Other research considers ventilation and air conditioning, cleanliness, smoothness of ride and security, either individually or collectively or as measures of an overall quality of service level. Measured separately, passengers' perceptions of comfort and safety are known to be relevant in their choice of PT services.

- Environmental Impact - Emissions, noise, visual pollution, vibration, dust, dirt, odour, waste and the consumption of natural resources are aspects of a PT service that might impact on the environment. Buehler [19] found that even when controlling for dissimilarities in socioeconomic factors and land-use form Germans are four times more likely to use environmentally friendly transport modes that Americans. Currently, being pro-environmental may only be a factor influencing a choice between PT or 
private vehicle use. In future, and in particular with supportive policy changes, the relative environmental impact of the particular mode could become a matter of preference for the PT user.

\section{Factors Influencing PT Users' Decisions}

The main choice a traveler has when making a journey is what mode he or she uses to get from the origin to the desired destination. This is a complex decision, and has been found to be a factor of trip characteristics, trip purpose, trip regularity, time of trip and the traveler's demographics such as age, gender, and income. A number of other factors have been found to be important when considering PT as a mode of transport including quality of a PT service, connectivity, fare costs, accessibility, and journey distance. Integrated multimodal transport systems which were convenient, accessible, comfortable, quick, affordable and safe, helped individuals view PT as a viable option. Factors influencing PT users' decisions can be categorised into three categories, psychological, operational and policy factors. These three categories are discussed below.

- Psychological factors: Psychological factors include the public's perception of PT, marketing techniques, habitual behaviors and pro-environment behaviors. For many a private car is viewed as more flexible, comfortable and convenient than PT. The private car is seen to be symbolic of an individual's status in society and driving one's vehicle is perceived as being pleasurable. Additionally, car users' underestimate their satisfaction with PT and inaccurately, recalling previous satisfaction when using PT resulting in a negative attitude towards PT which is difficult to change.

- Operational factors: Operational factors are typically controlled by the PT system operators and include safety, reliability, transfer time, information systems for users; fare systems and users comfort Personal safety can have a significant influence on an individual's route and mode choice. This places high importance on the security design and operation of transport stations. Stations are where there is the crime is most likely to occur when undertaking a PT trip, with users having greatest vulnerability at stations. Walking and waiting time is perceived as onerous. As such transfer penalties are commonly applied in transport modelling, to account for users' negative perception of PT transfers. For transfers to become a common part of a PT system, individual traveler behavior needs to change. This requires both the system to facilitate the change and the motivation of the user to make the change. The level of information provided to users can significantly alter the users' experience. Information can be provided prior to taking the trip, at the terminal, and on-board. Effective information systems, such as communicating when travelers need to disembark through mean such as smartphone applications, are seen to be beneficial for multi-modal trips [20].

- Policy factors: Policy factors are usually tied to the wider transport system and include push and pull strategies, legality, economic decisions, personalized travel plans and the integration of the different modal systems within the transport system. Chowdhury and Ceder [21] identified five main categories for integration of a PT system being (1) network integration, (2) fare and ticketing integration, (3) information integration, (4) physical integration of stations, and (5) integrated timed-transfers. When operating in an integrated manner, these factors can increase travelers' likelihood of taking PT.

\section{Methodology}

In traditional smartphone applications, users are given a set of paths and might select to sort the paths using given attributes, such as travel time (i.e., Google map), and possibly with a boundary related to an attribute, such as the maximum number of transfers (i.e., Rejseplanen App in Denmark). These apps, to some extent, cater passengers' preferences for different PT attributes, but cannot capture the trade-off between the various attributes and the stochasticity involved with passengers' preferences across time, space, weather, importance, mood, etc. Therefore, a future smartphone application should allow for passengers to indicate, at the time of a need for a ride, their preferences of different attributes and in return to obtain a set of best recommended routes/paths. To model this, we propose to use a weighted travel cost incorporating various PT attributes, and to use a K-shortest path algorithm to determine a set of paths adaptable to users' preferences. To attain this goal, passengers' route choice behaviour is taken also into account by developing a transit assignment model based on the K-shortest path concept. The overall framework of our analytical approach is illustrated in Fig. 1.

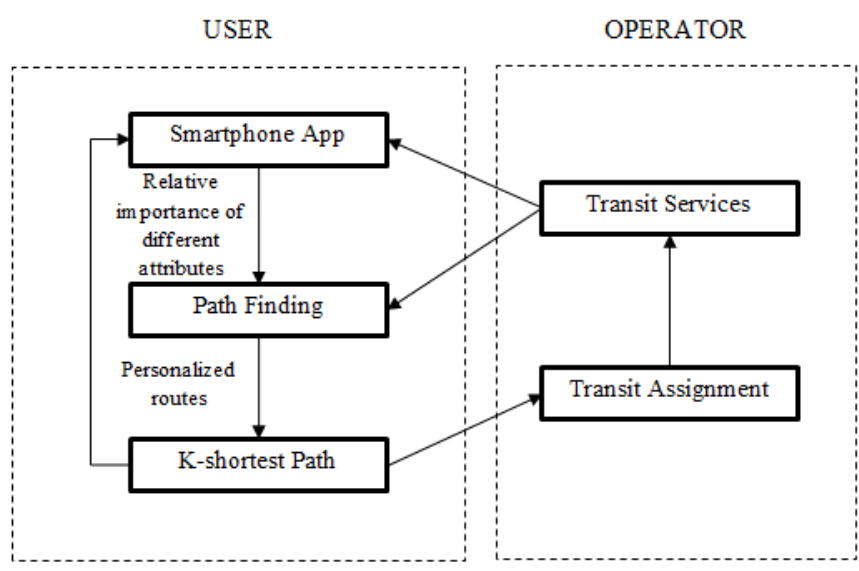

Figure 1. Methodological framework for the analysis.

From a user's perspective, a traveller could assess various PT-service information provided by the operator and specify the relative importance of different attributes of his/her route choice decision made via a smartphone. Given these parameters, a pathfinding component returns K-shortest path options to be displayed on the traveller's smartphone application. Considering passengers' real-time demand and the computational algorithmic effort, we suggest to compute the K-shortest path for all OD pairs offline and storing the resultant path sets in a database. For the offline computing, we could set all attributes equally important or calibrate these parameters from survey data. In real-time scenarios, the input 
of preferences is used to update the weighted costs of the $\mathrm{K}$-shortest path and obtain a new order of best recommended. At the same time, the set of best paths is utilized in a transit assignment model to predict the usages of PT services upon which the operator could implement operational tactics for improving the level of service provided. The mathematical formulations encapsulated in the analysis framework are briefly elaborated as follows.

\section{A. Weighted Path Travel Cost}

The weighted path travel cost associated with link $i j, d_{i j}$, is defined by

$$
d_{i j}=\sum_{m} \alpha^{m} c_{i j}^{m}, \forall i j
$$

where $c_{i j}^{m}$ is attribute $m$ associated with link $i j$ and $\alpha^{m}$ is the weighting parameter applied to attribute $m$ based on users' preferences. The weighted travel cost of path $p$ connecting nodes $o$ and $d$ is obtained via

$$
\pi_{p}^{o d}=\sum_{i j} \delta_{i j}^{p} d_{i j}, \forall o d, p \in P_{k}^{o d},
$$

where $\delta_{i j}^{p}$ is the path-link incidence matrix. If path $p$ passes link $i j, \delta_{i j}^{p}=1$, otherwise $\delta_{i j}^{p}=0$. Although the above equation does not explicitly include a variable of representing the transfer cost, the transfer cost is captured by adding dummy transfer links to the network.

\section{B. K-Shortest Path}

The K-shortest path algorithm is an extension of the Dijkstra shortest path algorithm that allows more than one path to be evaluated, finding not only the shortest path, but the subsequent shortest paths. The advantage is that additional constraints can be factored to find the 'new' shortest path, and that the user can make an informed decision based on the options presented.

\section{Transit Assignment Model}

The following assignment model is proposed. The model postulates that the number of passengers on a route depends on the services frequency of the first PT service as well as the weighted cost of the route,

$$
x_{p}^{o d}=\frac{f_{l_{p}}}{\sum_{l \in L_{o d}} f_{l}} \frac{\exp \left(-\theta \pi_{p}^{o d}\right)}{\sum_{p \in \Omega_{p}^{o d}} \exp \left(-\theta \pi_{p}^{o d}\right)} g^{\text {od }}, \forall o d, p \in P_{k}^{o d},
$$

where $x_{p}^{\text {od }}$ denotes the number of passengers travelling on path $p ; f_{l_{p}}$ represents the frequency of the first PT service associated with path $p ; L_{o d}$ denotes the set of transit lines departing from node $o ; P_{k}^{o d}$ represents the K-shortest path set connecting nodes $o$ and $d ; \Omega_{p}^{o d}$ is the set of paths that starting with the same PT service; $g^{\text {od }}$ is the travel demand between nodes $o$ and $d$.

The assignment model assumes that each passenger has a set $\Omega_{p}^{o d}$ of attractive paths (based on the K-shortest path procedure's outcome) and boards the first PT vehicle associated with these paths. In case the first PT vehicle is utilized by more than one path, the passenger is then assigned to a path using logit model. That is, this passenger will use the first arrived PT vehicle, but will use different transfers than the case in which the vehicle won't be utilized by other paths.

In the K-shortest path algorithm, the weighted factors are associated with an individual user, who uses a smartphone application to set his/her preferences. However, for the assignment model, an operator is more interested in the aggregated flow distribution instead of disaggregated route choice. Thus, in line with Nielsen [22], we adopt a simulation procedure to generate various passengers' preferences to compute average flows.

\section{CASE Study}

The case study considers the trips between the suburban center of New Lynn and Westhaven in Auckland's city center. The most direct route to the site is via Britomart, Auckland's central transport terminal. It is serviced by the western rail line, as well as a number of buses including express services. A number of connector bus services intersect the direct bus route at Point Chevalier providing opportunity for transfers. A map of the study area is shown in Fig. 2.

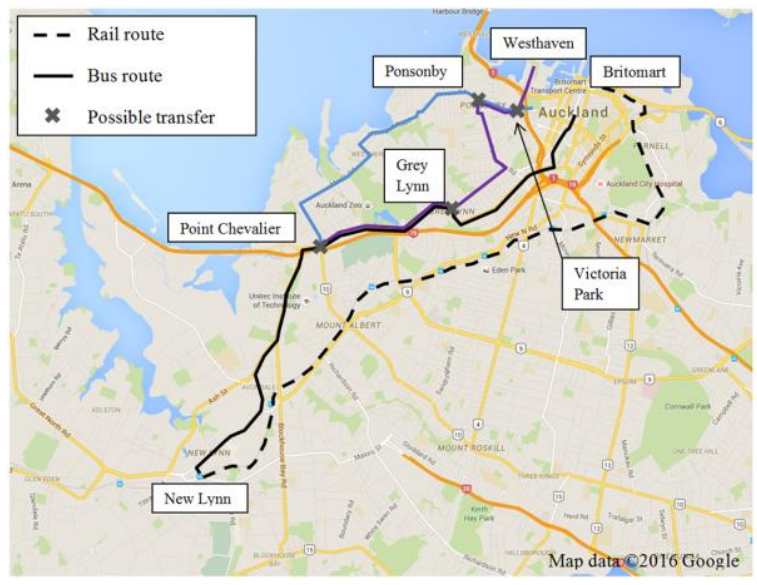

Figure 2. Auckland case study routes.

There are five sensible PT travel path options between New Lynn and Westhaven. These are outlined below:

- Path 1: Rail-Walk

- Path 2: Bus (New Lynn to Britomart)-Walk

- Path 3: Bus (New Lynn to Point Chevalier)-Bus (Point Chevalier to Victoria Park)-Walk

- Path 4: Bus (New Lynn to Point Chevalier)-Bus (Point Chevalier to Westhaven)-Walk

- Path 4: Bus (New Lynn to Grey Lynn)-Bus (Grey Lynn to Westhaven)-Walk.

Transfers at Victoria Park are not considered as these locations are within a $1.2 \mathrm{~km}$ walking distance to the final destination and as such transfers at stops are considered unrealistic. The case study is based on the morning commuter peak period. The five variables used to identify travelers' optimal travel route are waiting time, travel time, fare cost, 
walking time, and the number of transfers. Average waiting time is estimated using half of the headway for services which operate with frequencies less than 20 minutes. Where the frequencies are greater than 20 minutes the average wait time is assumed to be 10 minutes as passengers do not arrive randomly if service frequency is low. Travel times are calculated based on historical data for the direct route between New Lynn and Britomart. Due to time restrictions, data are not collected for the alternative routes and as such engineering judgement is used to predict the travel times on these routes. Fare cost is irrelevant to this case study. The PT fares in Auckland are based on fare boundaries irrespective of the mode of transport. As such element has minimal bearing on traveller's route choices.
The base values of the attributes considered are computed and shown in Table I, along with the path costs without user's weightings. The weighted path cost varies because of allowing for a passenger to specify his/her journey preferences. This can be used to identify the most suitable route for each user. The following example considers three different passengers, one perceives no difference across all the five attributes, one considers that fare is more important, and one does not like walking. The weighting parameters for the three passengers are presented in the left part of Table II. The corresponding weighted path costs are shown in the right part of the table.

TABLE I. BASE VALUES

\begin{tabular}{|c|c|c|c|c|c|c|c|c|c|c|}
\hline & \multicolumn{2}{|c|}{ Waiting } & \multicolumn{2}{|c|}{ Travel } & \multirow{2}{*}{$\begin{array}{c}\text { Fare } \\
\text { Value }(\$)\end{array}$} & \multicolumn{2}{|c|}{ Walking } & \multicolumn{2}{|c|}{ Transfer } & \multirow{2}{*}{$\begin{array}{l}\text { Path Cost } \\
\text { (\$) }\end{array}$} \\
\hline & $\begin{array}{l}\text { Value } \\
\text { (mins) }\end{array}$ & Value (\$) & $\begin{array}{l}\text { Value } \\
\text { (mins) }\end{array}$ & Value (\$) & & $\begin{array}{l}\text { Value } \\
\text { (mins) }\end{array}$ & Value (\$) & No. & Value (\$) & \\
\hline Path 1 & 5.0 & 5.0 & 50 & 25.00 & 5.5 & 10 & 10 & 0 & 0 & 45.5 \\
\hline Path 2 & 2.5 & 2.5 & 92 & 46.00 & 5.5 & 10 & 10 & 0 & 0 & 64.0 \\
\hline Path 3 & 10.0 & 10.0 & 91 & 45.50 & 5.5 & 12 & 12 & 1 & 1 & 74.0 \\
\hline Path 4 & 17.5 & 17.5 & 95 & 47.50 & 5.5 & 3 & 3 & 1 & 1 & 74.5 \\
\hline Path 5 & 17.5 & 17.5 & 96 & 48.00 & 5.5 & 3 & 3 & 1 & 1 & 75.0 \\
\hline
\end{tabular}

TABLE II. PATH RECOMMENDATIONS FOR TRAVELERS WITH DIFFERENT PREFERENCES

\begin{tabular}{|c|c|c|c|c|c|c|c|}
\hline & \multicolumn{3}{|c|}{ Value of Weighting Parameters } & \multirow[b]{2}{*}{ Path No. } & \multicolumn{3}{|c|}{ Weighted Path Cost (\$) } \\
\hline & Traveler 1 & Traveler 2 & Traveler 3 & & Traveler 1 & Traveler 2 & Traveler 3 \\
\hline$\alpha^{\text {wait }}$ & 0.2 & 0.1 & 0.1 & Path 1 & 9.1 & 7.3 & 9.6 \\
\hline$\alpha^{\text {travel }}$ & 0.2 & 0.1 & 0.1 & Path 2 & 12.8 & 9.2 & 11.4 \\
\hline$\alpha^{\text {fare }}$ & 0.2 & 0.6 & 0.1 & Path 3 & 14.8 & 10.2 & 13.4 \\
\hline$\alpha^{\text {walk }}$ & 0.2 & 0.1 & 0.6 & Path 4 & 14.9 & 10.2 & 9.0 \\
\hline$\alpha^{\text {Transfer }}$ & 0.2 & 0.1 & 0.1 & Path 5 & 15.0 & 10.3 & 9.0 \\
\hline \multicolumn{5}{|c|}{ Path Recommendation } & $1,2,3,4,5$ & $1,2,3,4,5$ & $4,5,1,2,3$ \\
\hline
\end{tabular}

The results state that Travelers 1 and 2 be recommended to use Path 1 as their best route, whilst Path 4 is the best route for Traveler 3. Although the path order for Travelers 1 and 2 is identical, the cost saving is different; it is measured by the difference between the best and the worst options. That is, for Travelers 1 and 2 the cost difference between the best and worst routes is $\$ 5.9$ and $\$ 3.0$, respectively. The larger the gap, the higher benefit for the traveler. It highlights the significance of the application to improve the users' satisfaction through the awareness of their benefits, based on their desired weightings.

Two scenarios are illustrated for the assignment results. The first scenario is without considering the weighted factors in which passengers were assigned to the selected path. In the second scenario, 1000 passengers' preferences are simulated.
In each simulation passengers are assigned to the path generated using the weighted path cost. Fig. 3 depicts the distribution of passengers' flows obtained for the two scenarios. That is, the flows of Paths 1, 2, and 5 are identical for the two scenarios. This is because of all these paths utilize one PT service and thus the flows are assigned based on the frequency of that service. For Paths 3 and 4, passengers transfer to different PT services after boarding the same line and thus the flows are distributed using the logit model. For the case in which weighted factors are considered, more passengers are assigned to Path 4 than Path 3 . These results imply that more passengers dislike the long walk time associated with Path 3 than Path 4 based on the base values of Table 3. The simulation results demonstrate that the proposed assignment model could reflect passengers' preference at an aggregated level. 


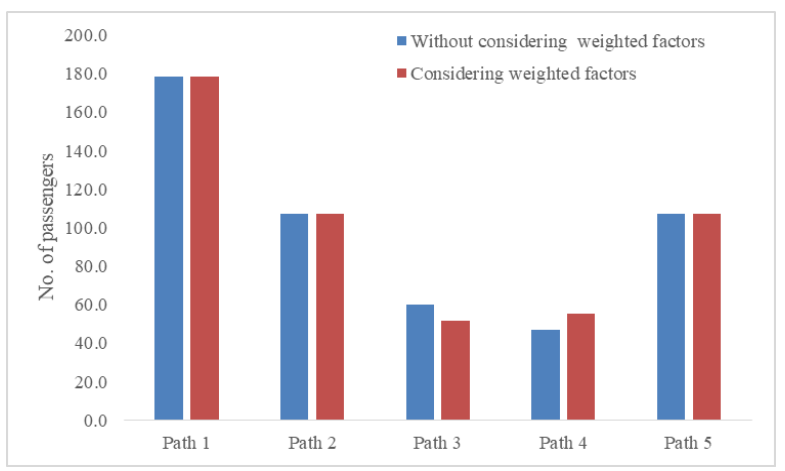

Figure 3. Assignment results.

\section{CONClusions}

The objective of this study is to look at how readily available smartphone-based information containing elements that might influence the decisions of which trip to select, can be personalized. The potential effect of personalized data availability for public transport (PT) users has been investigated by considering five key weighted factors: wait time, travel time, fare cost, walking time, and number of transfers. The methodology is based on finding the K-shortest path of travelers where the value of each link is comprised of the cost of the five weighted factors based on the users' preference. By incorporating weighted factors, user's preference may lean toward the $2^{\text {nd }}$, or $3^{\text {rd }}$, etc, shortest path compared with the case of not using weighted factors.

The findings of the case study in Auckland, New Zealand, in this research are limited by the consistent fare structure and the simplicity of the Auckland PT network. However, the analysis did find that applying a weighting based on user's individual preferences significantly reduces the cost of the trip and highlighted the optimal route for their needs. The smartphone application can significantly improve PT user's satisfaction through providing information that is specific to the users' preferences. This differs to the applications which are currently provided as these typically are focused on time only and do not consider other attributes which are important to PT users.

Given the technology available, the high use of smartphone devices, and the potential for user preferences to be taken into account, it is recommended that further research consider the following points:

- Application of the methodology with a stochastic shortest and K-shortest path algorithm to understand the variance in PT trips that occur in reality and incorporate passengers' risk-aversion attitude in the transit assignment model [23];

- Extending the options provided to users to cater for more real-time elements such as passengers' load profiles and network congestion;

- Undertaking a case study using more data to ensure the adequacy of the methodology;

- Incorporating the assignment model in the network design model.

\section{REFERENCES}

[1] A. Aguilera and V. Boutueil, Urban Mobility and the Smartphone: Transportation, Travel Behavior and Public Policy. Elsevier, 2018.

[2] T. Liu and A. Ceder, "Analysis of a new public-transport-service concept: Customized bus in China," Transport Policy, vol. 39, pp. 63-76, 2015

[3] C. L. Schweiger, Use and Deployment of Mobile Device Technology for Real-time Transit Information. Transportation Research Board (TRB), TRB's Transit Cooperative Research Program (TCRP) Synthesis \#91, Washington, DC, USA, 2011.

[4] New Zealand Transport Agency, Position Statement on Intelligent Transportation Systems - Responding to the Opportunities. Wellington: New Zealand Government, 2014.

[5] P. Cebon and D. Samson, "Using real-time Information for Transport Effectiveness in Cities," City, Culture and Society, vol. 2, no. 4, pp. 201-210, 2011.

[6] S. Siuhi and J. Mwakalonge, "Opportunities and challenges of smart mobile applications in transportation," Journal of Traffic and Transportation Engineering (English Edition), vo. 3, no. 6, pp. 582-592, 2016

[7] Global Mass Transit Report, Smartphone Apllications in Transit Services: Growing Popularity. Retrieved from https://www.globalmasstransit.net/archive.php?id=16210, 2019.

[8] M. Cantwell, B. Caufield, and M. O'Mahony, "Examining the factors that impact public transport commuting satisfaction," Journal of Public Transportation, vol. 12, no. 2, pp. 1-21, 2009.

[9] W.T. Lai and C.F. Chen, "Behavioural intentions of public transit passengers -The roles of service quality, percieved value, satisfaction and involvement," Transport Policy, vol.18, no. 2, pp. 318-325, 2011.

[10] S. Carmien, M. Dawe, G. Fischer, A. Gorman, A. Kintsch, and Jr, J.F. Sullivan, "Socio-technical environments supporting people with cognitive disabilities using public transportation," ACM Transactions on Computer-Human Interaction (TOCHI), vol. 12, no. 2, pp. 233-262, 2015.

[11] L. Eboli, and G. Mazzula, "Performance indicators for an objective measure of public transport service quality," European Transport, no. 51, paper no. 3, pp. 1-21, 2012

[12] D. Estergar-Kiss, and C. Csiszar, "Evaluation of mulitmodal journey planners and defintion of service levels," International Journal of ITS Research, no.12, pp. 154-165, 2015.

[13] D. A. Walton and S. Sunseri. "Factors influencing the decision to drive or walk short distances to public transport facilities," International Journal of Sustaiable Transportation, vol. 4, no. 4, pp. 212 -226, 2010.

[14] A. Ceder, Y. Net and C. Coriat, "Measuring public transport connectivity performance applied in Auckland, New Zealand," Transportation Research Record, no. 2111, pp. 139-147, 2009.

[15] T. Liu and A. Ceder, "Communication-based cooperative control strategy for public transport transfer synchronization," Transportation Research Record, no. 2541, pp. 27-37, 2016.

[16] L.W. Verhoef, "A new conceptual structure for travel information," Applied Ergonomics, vol. 24, no. 4, pp. 263-269, 1993

[17] L. Eboli and G. Mazzulla. "How to capture the passengers' point of view on a transit service through rating and choice options," Transport Reviews, vol. 30, no. 4, pp. 435-450, 2010.

[18] P. Vovsha, M.G.S. Oliveira, W. Davidson, C. Chu, R. Farley, M. Mitchell, G. Vyas, "Statistical analysis of transit user preference including in-vehicle crowding and service reliability," Proceedings of 93rd Transportation Research Board Annual Meeting, Washington DC, United States of America, 2014.

[19] R. Buehler, "Determinants of transport mode choice: a comparison of Germany and the USA," Jounral fo Transport Geography, vol. 19, pp. 644-657, 2011.

[20] S. Bachok, "What do passengers need out of public transport information systems?" The 29th Conference of Australian Institute of Transport Research, Adelaide, Australia, 2007.

[21] S. Chowdhury and A. Ceder, "Users' willingness to ride an integrated public-transport service: A literature review," Transport Policy, vol. 48, pp.183-195, 2016.

[22] O.A. Nielsen, "A stochastic transit assignment model considering differences in passengers' utility functions," Transportation Research Part B, vol. 34, no. 5, pp. 377-402, 2000.

[23] Y. Jiang and W.Y. Szeto. "Reliability-based stochastic transit assignment: Formulations and capacity paradox," Transportation Research Part B, vol. 93, pp. 181-206, 2016. 